\title{
Avaliação Sanitária do Setor de Quarentena do Centro de Triagem de Animais Silvestres de Goiânia (Goiás)
}

\author{
Ronny Morais, Cleber Costa, Eliana Bravo, Antônio Santana, \\ Sebastião Félix, Georgia Sant'Ana, Luiz Baptista \& Carlos Sant'Ana
}

Este trabalho teve como objetivo analisar a situação sanitária da quarentena e dos recintos de confinamento das aves do Centro de Triagem de Animais Silvestres (CETAS) de Goiânia. Para cada um dos dois tipos de ambientes (gaiolas e recintos abertos) foram coletadas mensalmente dez amostras de água dos bebedouros e de amostras do chão. Em geral, houve uma maior frequência de E. coli e de Salmonella sp na água dos bebedouros e nas amostras do chão dos recintos abertos quando comparadas com as gaiolas, o que indica que a sua maior área e maior densidade de indivíduos podem dificultar a limpeza e a desinfecção.

Palavras-chaves: aves silvestres; microbiota; zoonoses.

This study aimed to analyze the health conditions in the quarantine sector and enclosures for bird confinement by CETAS - Goiânia. Ten samples of water from drinking troughs and ground were collected monthly in each of the two types of environment (open cages and enclosures). In general, there was an increased frequency of E. coli and Salmonella spp in the water of drinking troughs and ground from open environments when compared to the cages, indicating that a larger area and higher density of individuals may difficult to clean and disinfect the environments.

Keywords: wild birds; microbiota; zoonotic diseases. 


\section{Introdução}

O território brasileiro abriga uma das maiores riquezas em avifauna quando comparada com outras regiões do mundo, totalizando mais de 1700 espécies, das quais mais de $10 \%$ são consideradas endêmicas, o que torna o país um dos mais importantes em relação a investimentos em conservação ${ }^{1}$. Em contrapartida, o país desperta forte interesse dos traficantes de animais silvestres ${ }^{2}$, o que tem contribuído de forma significativa para os altos índices de apreensões obtidas pelos órgãos competentes. Dentre essas apreensões, as aves correspondem a $82 \%$ dos $\operatorname{casos}^{3}$, sendo as ordens Passeriformes, Piciformes e Psitaciformes as mais encontradas, devido à grande diversidade de cores, à sua capacidade de imitar sons e ao valor econômico associado, como a venda de couro, penas e ovos ${ }^{4,5,6}$.

Os animais apreendidos são encaminhados aos respectivos Centros de Triagem de Animais Silvestres (CETAS), que respondem pelas informações dos animais recebidos por agentes da fiscalização do IBAMA ou das Polícias Florestais e ainda pelos espécimes provenientes de entrega voluntária. Este órgão é responsável pela guarda desses animais; por seu tratamento clínico; por sua manutenção e por sua destinação final, seja essa uma soltura em áreas de preservação; uma destinação para criadores cadastrados como zoológicos e parques, ou ainda, uma guarda como fiel depositário, feitas por pessoas físicas cadastradas e reconhecidas como idôneas, segundo processos próprios do IBAMA ${ }^{3}$.

Desde a sua implantação, o CETAS - Goiânia tem recebido um número crescente de espécies advindas do tráfico. $\mathrm{Na}$ admissão, estes animais passam por uma triagem e são levados para o setor de quarentena. Após a verificação das condições em que se encontram, os animais são encaminhados aos respectivos recintos ${ }^{3}$.

A Organização Mundial de Sanidade Animal - OIE preconiza que a Estação de Quarentena seja um local controlado pela autoridade veterinária e que mantenha os animais isolados, sem nenhum contado direto ou indireto com outros animais para evitar a transmissão de agentes patogênicos de importância epidemiológica. Neste período, os animais são submetidos à observação, provas de diagnóstico e tratamento ${ }^{7}$.

A legislação para Zoológicos e Criadouros no Brasil estabelece a necessidade de executar a quarentena de animais silvestres, porém, não existe protocolo específico para esta finalidade. Neste aspecto, a Sociedade Paulista de Zoológicos, propõe um Programa de Quarentena mínimo a ser executado pelos zoológicos e demais unidades receptoras de animais, destacando que a quarentena deve ser vista como um Programa, visando à preservação da saúde dos animais, funcionários e visitantes de cada instituição

Para o estabelecimento do programa de quarentena, os itens de maior importância correspondem à identificação do animal; definição do tempo de quarentena para a espécie; protocolos de exames clínicos; protocolo de exames laboratoriais; protocolos de vermifugações e imunizações; destinação dos resíduos sólidos e efluentes e protocolos de medidas sanitárias como vazio sanitário; desinfecção de fômites e equipamentos; escolha dos desinfetantes; controle de pragas e de animais sinantrópicos e criação de barreiras estruturais de desinfecção ${ }^{8}$.

No entanto, nem todos os zoológicos e criadouros possuem locais específicos para realizarem a quarentena ou essa é mantida em local inadequado. Estes fatos são apontados como pontos críticos no processo de isolamento dos animais. Os planos e procedimentos de segurança e saúde animais devem ser elaborados, conforme particularidades regionais e a sua implantação e manutenção requerem disciplina administrativa ${ }^{9}$.

Alguns cuidados com a estrutura física de um criadouro, como quarentena e recintos, são de grande importância para evitar possível transmissão de doenças ao plantel. Estas medidas estão estreitamente relacionadas com a saúde das aves, aliadas às boas práticas de manejo. $\mathrm{O}$ setor de quarentena deve ser mantido à certa distância dos viveiros das outras aves já existentes no local e contar com materiais e funcionários exclusivos. Durante a quarentena, é imprescindível a observação diária das aves e a pesquisa de sinais clínicos compatíveis com as afecções. Durante este período, também é realizada a profilaxia que deve ser estabelecida para cada criadouro. Passado o período referido e estando as aves aptas, elas podem ser transferidas para o plantel permanente ${ }^{10}$.

O ambiente de um Centro de Triagem de Animais Silvestres continua sendo propício à disseminação de doenças, muitas delas de potencial zoonótico e a 
quarentena é imprescindível para impedir a disseminação de agentes patógenos e de doenças em coleções de espécies selvagens raras e muitas vezes importantes em programas de reprodução ${ }^{11}$.

Dessa forma, a situação sanitária dos animais, bem como a dos recintos, torna-se um aspecto relevante, pois a forma de captura, o transporte, as condições inadequadas de higiene, a má alimentação e a aglomeração de indivíduos favorecem a contaminação e a dispersão de doenças. Apesar dos esforços dos profissionais do CETAS na manutenção de um rigoroso manejo sanitário, o ambiente em cativeiro continua sendo propício à disseminação de inúmeras enfermidades, muitas delas consideradas como zoonoses ${ }^{11,12,13}$. Esse aspecto pode ser estendido a outros estabelecimentos que possuem animais silvestres, pois animais em cativeiro mascaram sinais clínicos, mesmo estando infectados com agentes etiológicos, constituindo, desta forma, importantes fontes de infecção ${ }^{14}$.

Assim, o presente trabalho teve como objetivo analisar a situação sanitária do setor de quarentena e dos recintos destinados ao confinamento das aves no CETAS - Goiânia, a fim de compará-los com a literatura vigente.

\section{Metodologia}

A presente pesquisa foi realizada no CETAS $\left(16^{\circ} 35^{\prime}\right.$ $\left.51 \mathrm{~S} \mathrm{e} 49^{\circ} 11^{\prime} 57^{\prime \prime} \mathrm{O}\right)$ localizado às margens da BR 153 , entre o bairro Guanabara e o Parque Estadual Altamiro de Moura Pacheco na cidade de Goiânia, Goiás, no período de fevereiro a junho de 2012. Neste período, foi analisada a situação sanitária dos ambientes destinados ao confinamento de aves (araras, periquitos, corujas, gaviões e tucanos) apreendidas pelo CETAS.

Os referidos ambientes foram divididos em duas categorias, recintos abertos e gaiolas. Os recintos abertos localizam-se em uma área externa, possuem dimensões variáveis, o que possibilita a acomodação de um número maior de indivíduos e não apresentam nenhuma forração específica, permitindo o contato direto dos animais com o solo. Já as gaiolas permanecem em uma área restrita, destinada à quarentena dos animais, possuem tamanhos variados, mas em sua maioria abrigam apenas um indivíduo. Todas as gaiolas apresentam a grade de chão, o que evita o contato direto das aves com excretas e restos de comida. Em cada ambiente, foi coletado mensalmente um total de dez amostras de água e amostras do chão. As amostras de água foram coletadas nos bebedouros dos animais e as amostras do chão foram obtidas diretamente do fundo das gaiolas e do chão dos recintos.

As amostras microbiológicas foram coletadas por meio de swabs estéreis e imersos em tubo com $10 \mathrm{~mL}$ de solução salina a $0,9 \%$ e acondicionados sob refrigeração para o isolamento e identificação de bactérias Escherichia coli e Salmonella spp. O material foi encaminhado ao laboratório de análises microbiológicas da Faculdade de Tecnologia SENAI Roberto Mange, em Anápolis, Goiás.

As amostras coletadas foram replicadas através da técnica de diluição $\left(10^{-1}\right.$ e $\left.10^{-2}\right)$, totalizando 80 amostras por coleta e distribuídas em tubos de ensaio, contendo solução salina. Para detecção presuntiva de E. coli e Salmonella spp, $1 \mathrm{~mL}$ da suspensão foi inoculada em placas de petri, contendo respectivamente ágar MacConkey e ágar Verde Brilhante e incubadas a $35^{\circ}$ C por 24 horas. Na identificação preliminar, as colônias típicas de E. coli, apresentaram coloração púrpura e foram inoculadas em placas de EMB (MERCK, Germany) e incubadas a $35^{\circ} \mathrm{C}$ por 24 horas. Após este período, foram feitas as contagens das colônias típicas, utilizando-se o aparelho contador de colônias ${ }^{15}$.

As colônias típicas de Salmonella spp apresentaram coloração de marrom a preta e foram inoculadas com o auxilio de alça de platina em tubos contendo Agar TSI (MERCK, Germany) e incubadas a $35^{\circ} \mathrm{C}$ por 24 horas. A reação positiva típica de Salmonella spp, neste meio, é uma superfície alcalina (vermelha) e fundo ácido (amarelo) com ou sem produção de H2S (escurecimento do ágar). Uma alíquota do conteúdo dos tubos de ensaio positivos foi transferida para as placas de petri, contendo Agar EMB e levadas à estufa por 24 horas a $35^{\circ} \mathrm{C}$. Foram feitas as contagens das colônias típicas, utilizando-se o aparelho contador de colônias ${ }^{16,15}$.

A análise estatística para comparar os valores das unidades formadoras de colônias (UFC) dos respectivos microrganismos entre o período em estudo foi realizada pelo teste de ANOVA de medidas repetidas. Para execução do cálculo estatístico foi utilizado o software STATISTICA $®$ versão 7.0 (Statsoft, Inc). Antes das análises, os dados foram logaritmizados para estabilizar as variâncias e o nível de significância assumido foi de $\alpha=0,05$. 
A pesquisa foi autorizada pelo Instituto Brasileiro de Meio Ambiente e Recursos Renováveis como parte integrante do projeto ASAS em parceria com a Faculdade de Tecnologia SENAI Roberto Mange.

\section{Resultados e Discussão}

A detecção presuntiva de $E$. coli presente na água (dos recintos em área aberta e gaiolas), no período em estudo, apresentou maior variação no mês de junho. Houve presença maior de E. coli na água dos recintos em área aberta quando comparadas com as gaiolas, exceto no mês de junho em que a presença de E. coli nas gaiolas superou os valores obtidos para os recintos (Figura 1). Já a detecção presuntiva de $E$. coli presente nas amostras do chão (dos recintos de área aberta e gaiolas) no período em estudo apresentou maior variação nos meses de fevereiro, março e junho. Houve presença maior de $E$. coli nos recintos abertos quando comparadas com as gaiolas (Figura 2).

A detecção presuntiva de Salmonella $s p$ presente na água, por sua vez, apresentou maior variação no mês de abril. Houve presença maior de Salmonella spp na água dos recintos localizados em áreas abertas, quando comparados com as gaiolas, exceto nos meses de abril e maio, em que esta variação foi maior para as gaiolas (Figura 3).

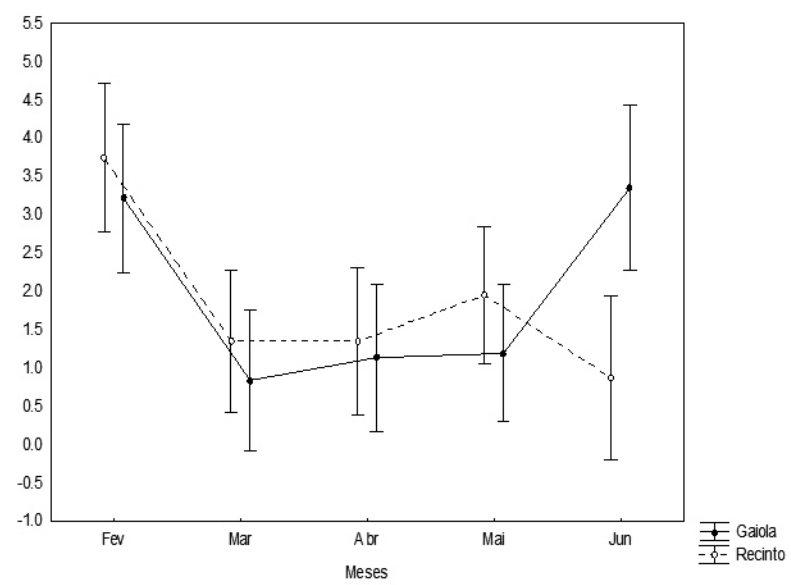

Figura 1. Distribuição mensal de E. coli na água nos dois tipos de ambientes (gaiolas e recintos abertos).

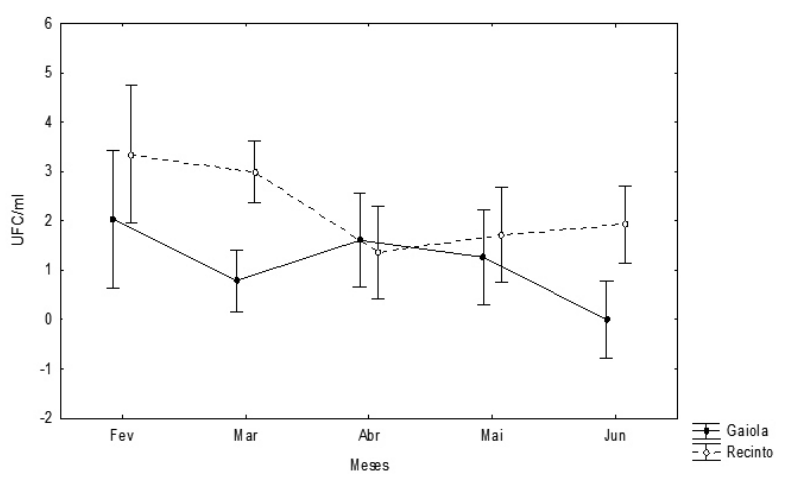

Figura 2. Distribuição mensal de E. coli no chão dos dois tipos de ambientes (gaiolas e recintos abertos).

Já a detecção presuntiva de Salmonella spp presente nas amostras do chão (dos recintos abertos e gaiolas) apresentou maior variação nos meses de fevereiro, março, abril e junho. Da mesma maneira como ocorreu com E. coli, houve presença maior de Salmonella spp no chão dos recintos abertos, quando comparados com as gaiolas, embora no mês de maio, ambos os locais tenham apresentado aproximadamente os mesmos valores (Figura 4).

As bactérias do gênero Salmonella $s p$ e E. coli são frequentemente encontradas colonizando a microbiota de aves silvestres e geralmente estão associadas a doenças intestinais ou quadros de septicemia, mas sua infestação deve-se aos processos que possam provocar um desequilíbrio na microbiota destas aves, como estresse decorrente do aprisionamento; uso indiscriminado de antibióticos; alterações na dieta ou problemas advindos do manejo ambiental ${ }^{17,18,19,20,21}$. Desta forma, mesmo que a bactéria esteja presente, as manifestações clínicas da enfermidade só aparecerão em situações específicas.

$\mathrm{Na}$ transmissão horizontal, as aves se infectam por via oral e tem sido grande a especulação de que seu alimento atue como importante veículo de contaminação. As rações e suas matérias-primas, principalmente, as de origem animal, apresentam altas taxas de contaminação por Salmonella $s p{ }^{22}$. Dependendo da dieta da ave, esta pode ser alimentada com hortifrutigranjeiros (mamão, 


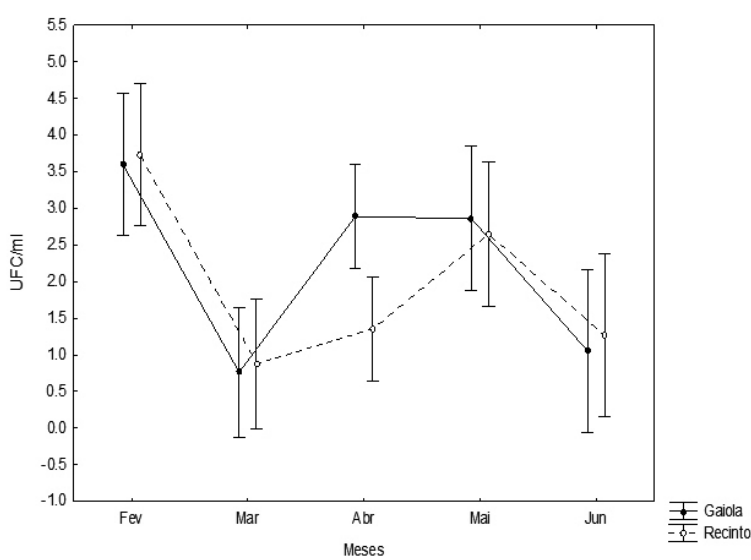

Figura 3. Distribuição mensal de Salmonella sp na água nos dois tipos de ambientes (gaiolas e recintos abertos).

banana, maçã, laranja, jiló, melancia etc.) sementes (alpiste, painço, girassol etc) ou ração comercial própria para a espécie (principalmente psitacídeos e ranfastídeos). Portanto, deve haver um controle rigoroso em relação à procedência destes alimentos, bem como do seu manuseio pelos tratadores. Além disso, a contaminação do ambiente através da eliminação das excretas e por via aerógena tem sido um fator preponderante no processo ${ }^{23}$.

De acordo com Wierup e Häggblom ${ }^{24}$, procedimentos efetivos de Análise de Perigos e Pontos Críticos de Controle (APPCC) devem ser implantados, baseados no controle e em ações corretivas para a redução da contaminação alimentar por Salmonella spp. Esses procedimentos devem ser utilizados no CETAS, já que se diagnosticou infecção por Salmonella spp e pelo fato desse patógeno ser transmitido por alimentos contaminados ${ }^{25,26}$.

A adoção de boas práticas, quando monitoradas, pode ser economicamente viável para reduzir a presença e/ou a circulação de microrganismos nos setores de manipulação e preparo de alimentos, em abrigos de animais, bem como oferecer condições para redução dos gastos com diagnóstico, tratamento e agravos à saúde animal. Dessa forma, a higienização de frutas e verduras, a aquisição de produtos de origem animal de boa qualidade e inspecionados são medidas importantes para o controle de patógenos de veiculação alimentar, como é o caso da Salmonella spp ${ }^{27}$.

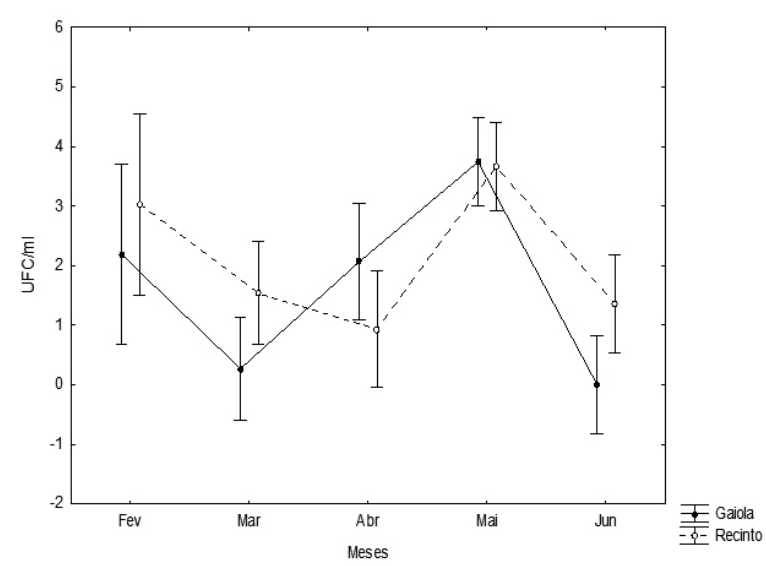

Figura 4. Distribuição mensal de Salmonella sp no chão dos dois tipos de ambientes (gaiolas e recintos abertos).

Um aspecto importante a ser considerado é que os animais de vida livre são soltos imediatamente após o resgate e aqueles que necessitam de um período de reabilitação, como os passeriformes, permanecem de 4 a 6 meses em cativeiro. Já os psitacídeos, ranfastídeos e rapinantes permanecem por períodos de 12 a 18 meses, em média.

Para o controle sanitário dos recintos contra os ectoparasitas e ovos e larvas de endoparasitas, não é realizado um vazio sanitário, o que dificulta a remoção mecânica de sujidades. Portanto, a limpeza destes locais é realizada mesmo com a presença dos animais. As gaiolas presentes na área de quarentena passam por um processo de limpeza diária para a retirada de restos de comida e excretas dos animais. Já a desinfecção é feita esporadicamente, de preferência após a retirada do animal da gaiola e, para tanto, é utilizado o hipoclorito de sódio. Este procedimento é corroborado pelo trabalho de Moraes $^{28}$ que, após verificar a eficácia na utilização de diversos produtos saneantes, como álcool etílico a $70 \%$, monopersulfato e hipoclorito de sódio na desinfecção de um ambiente de quarentena, constatou que este último apresentou os melhores índices gerais de desempenho.

A limpeza prévia, realizada com água, sabão e ação mecânica, potencializa as ações dos desinfetantes, por permitir uma redução considerável dos microrganismos presentes, além de eliminar completamente a matéria 
orgânica presente no material contaminado ${ }^{29,30}$. Estimase que esses microrganismos possam permanecer por um longo período em um local, mesmo sem a presença de animais, caso as condições sejam favoráveis para o seu crescimento. Além disso, essas podem ser disseminadas por vetores, como roedores ou pequenos insetos. Portanto, a limpeza; a desinfecção ambiental; o vazio sanitário e o combate de vetores são ações importantes na prevenção e controle da contaminação ${ }^{31,32,20}$.

As aves infectadas por Salmonella sp podem excretar a bactéria por longos períodos, variando de semanas a meses. O confinamento de aves em gaiolas ou outro recinto, sob efeito de elevada densidade populacional, pode resultar em ciclos de salmonelose pela disseminação da bactéria através de seus excretas. Assim, ambientes com alta umidade podem proporcionar uma situação favorável à disseminação da doença ${ }^{33}$.

$\mathrm{O}$ curso da doença nas aves depende do número de microrganismos, do sorotipo, da idade, da espécie e das condições em que se encontra o hospedeiro. Normalmente, aves jovens são os membros mais afetados, ocorrendo alta taxa de mortalidade nesta fase. As Aves de vida livre podem ser portadoras assintomáticas e atuarem como reservatório para aviários, bem como aves que sobreviveram a um surto. Neste sentido, a maior preocupação é se elas podem servir de reservatórios para sorotipos de bactérias exóticas, o que poderia causar surtos devastadores ${ }^{34,35}$.

Portanto, aves destinadas a programas de soltura ou reintrodução devem passar por um processo de acompanhamento rigoroso através de análises clínicas. Entretanto, os exames clínicos, diversas vezes, são realizados apenas quando as aves apresentam sinais clínicos ou quando já saíram da quarentena e estão sendo preparadas para a soltura. Isto se deve ao fato de que muitas instituições não possuem contratos para a realização periódica de exames e a frequência e o tipo de exame podem ser alterados ao longo dos anos, tornando-se incipientes. Estima-se que há uma realização de exames semestral para identificação de E. coli e Salmonella sp. Associa-se a esta avaliação uma análise dos locais em que estes animais habitam até o momento da soltura, na tentativa de garantir maior qualidade e eficiência no controle dos patógenos ${ }^{36,37}$.

Alguns autores relatam a presença de E. coli em aves silvestres no ambiente natural, apontando para a possibilidade da fonte da infecção estar presente nos ninhos, pois estes acumulam geralmente excretas e matéria orgânica, além de serem utilizados por espécies oportunistas, favorecendo a contaminação ${ }^{38}$. Este trabalho corrobora os resultados obtidos em que se observa uma maior incidência de bactérias nos recintos abertos em relação às gaiolas, pois estas passam por um processo de limpeza e desinfecção periódica para evitar o acúmulo de resíduos como excretas, água, restos de alimento e penas. Por serem menores e acomodarem apenas um indivíduo, a limpeza das gaiolas torna-se mais viável. Os recintos abertos possuem maior área e são destinados a uma densidade maior de indivíduos, o que dificulta sua limpeza e desinfecção, pois nem sempre é possível fazer o manejo adequado das espécies.

Um fator importante que pode ser um dos condicionantes para a difusão dos microrganismos entre os indivíduos é a translocação de um hospedeiro infectado a um novo local em que há hospedeiros suscetíveis. Como no CETAS ocorre uma alta demanda de indivíduos, oriundos das apreensões, a entrada de um novo indivíduo portador no grupo pode ser um veículo de contaminação, já que na quarentena, os animais não são submetidos a exames clínicos regulares.

\section{Considerações Finais}

O conhecimento sobre a microbiota de aves silvestres no Brasil ainda é incipiente, mas se sabe que elas podem abrigar um importante grupo de patógenos de interesse zoonótico, o que as torna um grupo de relevante interesse para a saúde pública ${ }^{30}$. A investigação da diversidade de microrganismos pertencente à microbiota destas espécies é uma importante ferramenta na elucidação da etiologia das doenças e serve como aporte para fomentar discussões e prover medidas de controle e prevenção de infecções ${ }^{39,21}$.

Desta forma, há uma necessidade no investimento de ações voltadas para o manejo adequado destas espécies, bem como no controle sanitário dos respectivos locais destinados à sua acomodação até a eventual soltura. As medidas de controle de infecção devem seguir um padrão rigoroso para garantir os padrões sanitários adequados, visando à melhoria da qualidade de vida destes indivíduos.

De acordo com Moraes ${ }^{28,}$ a contagem de bactérias 
heterotróficas pode ser considerada como a forma mais rápida e fácil de verificar a eficácia da higienização e desinfecção em locais destinados à quarentena. Este método é de baixo custo, de resultados rápidos (48 horas), o que o torna elegível como parâmetro para a verificação de possíveis falhas no processo. Desta forma, o presente trabalho corrobora a metodologia utilizada para detecção de microorganismos presentes nos ambientes em estudo. Vale ressaltar que a obtenção de parâmetros permite auxiliar na tomada de decisão e possibilitar possíveis correções de procedimentos de higienização e desinfecção, antes que possa ocorrer um comprometimento do processo de isolamento do setor de quarentena.

\section{Agradecimentos}

Ao CETAS-Goiânia pelo apoio técnico, logístico e pela disponibilização de dados para a execução do trabalho. À Superintendência Estadual do IBAMA em Goiás pelo financiamento do projeto ASAS. Ao SENAIGO pelo apoio técnico e logístico. Aos alunos e técnicos da Faculdade de Tecnologia SENAI Roberto Mange pelo apoio técnico prestado. À Nélia Marinho de Sousa Barreto, diretora em saúde da Prefeitura Municipal de Anápolis pelo apoio ao trabalho.

\section{Referências}

1. Barbosa, J. A. A.; Nóbrega, V. A.; Alves, R. R. N. Rev. Biol. Ciênc. Terra 2012, 10, 39.

2. RENCTAS. Relatório nacional sobre o tráfico de fauna silvestre. Rede Nacional de Combate ao Tráfico de Animais Silvestres, Brasília, 2002.

3. Instituto Brasileiro do Meio Ambiente e dos Recursos Naturais Renováveis - IBAMA. Campanha Nacional de Proteção à Fauna Silvestre - Relatório Semestral. Disponível em: http://www. ibama.gov.br. Acessado em abril de 2013.

4. Pagano, I. S. A.; Sousa, A. E. B. A.; Wagner, P. G. C.; Ramos. R. T. C. Ornithologia 2009, 3, 132.

5. Marinho, M.; Táparo, C. V.; Silva, B. G.; Tencate, L. N.; Perri, S. H. V. Veterinária e Zootecnia 2010, 17, 288.

6. Bezerra, D. M. M.; Araújo, H. F. P.; Alves, R. R. N. Tropical Conservation Science 2012, 5, 50.

7. Organização Mundial De Sanidade Animal. Puestos fronterizos y estaciones de cuarentena en el país importador. Cap. 5.6. Código Sanitário para los Animales Terrestres. 2008.
8. Sociedade Paulista De Zoológicos. Programa de quarentena. Disponível em: < http://www.spzoo.org.br/quarentena.htm>. Acessado em maio de 2013.

9. Cubas, Z. S. Ciência Veterinária Tropical 2008, 11, 174.

10. Allgayer, M. C.; Cziulik, M. Rev. Bras. Reprod. Animal 2007, 3, 344.

11. Silva, J. C.; Corrêa, S. H. R. Manejo Sanitário e Biosseguridade. Em Tratado de Animais Selvagens Medicina Veterinária. Cubas, Z. S.; Silva, J. C. R.; Catão-Dias, J. L. 1. ed., Roca: São Paulo, 2007.

12. Schloegel, L. M.; Daszak, P.; Naya, A. Natureza \& Conservação 2005, 3, 29.

13. Kelly, T. R.; Hawkins, M. G.; Sandrock, C. E.; Boyce, W. M. Journal of Avian Medicine and Surgery 2008, 22, 1.

14. Cubas, Z. S. Off. Int. Epizoot. Sci. Tech. Rev. 1996, 15, 267.

15. Filho, G. N. S.; Oliveira, V. L. Microbiologia: manual de aulas práticas. 2 ed., UFSC: Florianópolis, 2007.

16. Silva, N.; Junqueira, V. C. A.; Silveira, N. A. S. Manual de Métodos de Análise Microbiológica de Alimentos. Varela: São Paulo, 2001.

17. Mattes, B. R., Consiglio, S. de A. S; de Almeida, B. Z.; Guido, M. C.; Orsi, R. B.; da Silva, R. M.; Costa, A.; Ferreira, A. J. P.; Knöbl, T. Arq. Inst. Biol. 2005, 2, 13.

18. Aguilar, R. F.; Hernández, S. M.; Hernández, S. J. Em Atlas de medicina, terapêutica e patologia de animais exóticos. Interbook: São Caetano do Sul, 2006.

19. Marietto-Gonçalves, G. A.; Lima, E. T., Sequeira, J. L., AndreattiFilho, R. L. Revista Brasileira de Saúde Produção Animal 2007, 1,56 .

20. Godoy, S.N. Em Tratado de animais selvagens - medicina veterinária. Roca: São Paulo, 2007.

21. Fraga, M. E.; Medeiros, M. E. S.; Neves, D. M. Rev. Bras. Med. Vet. 2011, 33, 68 .

22. Andreatti-Filho, R. L. Rev. Educ. Contin. (CRMV-SP) 2001, 4, 90.

23. Rupley, A. E. Manual of avian practice. Elsevier: Health Sciences Division, 1997.

24. Wierup, M.; Haggblom, P. Acta Veterinaria Scandinavica 2010, 15,1 .

25. Weir, E.; Doré, K.; Currie, A. Canadian Med. Assoc. or its Licensors 2004, 2, 127.

26. Miller, T.; Prager, R.; Rabsh, W.; Fehlhaber, K.; Voss, M. Lohomann Information Cuxhaven 2010, 2, 27.

27. Ballian, S. C.; Telles, E. O.; Gomes, M. S.; Azevedo, V. L.; Sanchez, A. S.; Souza, O. B.; Grespan, A.; Ferreira, A. J. P.; Pinheiro, S. R. Veterinária e Zootecnia (Botucatu) 2006, 2, 208. 
28. Moraes, W. Análise de crescimento bacteriano em um quarentenário de psitacídeos. Dissertação de Mestrado, Universidade Federal do Paraná, 2011.

29. Souza, A. C. S.; Pereira, M. S.; Rodrigues, M. A. V. Rev. Latinoamer. Enferm. 1998, 3, 95.

30. Ikuno, A. A.; Gama, N. M. S. O.; Gustalli, E. A. L.; Guimarães, M. B.; Ferreira, V. C. A. Anais $35^{\circ}$ Cong. Bras. de Med. Vet., 2008.

31. Riemann, H; Kass, P; Cliver, D. Science 2000, 287, 1754.

32. Rabsch, W; Tschape, H; Baumler, A. J. Microbes and Infection 2001, 3, 237.

33. Friend, M. Em Field manual of wildlife diseases. Friend, M.; Frason, C. Biological Resources Division: Washington, 1999.

34. Gerlach, H. Bacteria. Em Avian medicine: principles and application. Ritchie, B. W.; Harrison, G. J.; Harrison, L. B. Wingers: Florida, 1994.

35. Weill, F. X. Revue Francophone des Laboratoires 2008, 400, 37.

36. Franco, B. D. G. M.; Microbiologia dos Alimentos. Atheneu: São Paulo, 2002.

37. Silva, J. Associação Brasileira de Veterinários de Animais Selvagens, 2004.

38. Bangert, R. L.; Cho, B. R.; Widders, P. R.; Ehlers, M. N. Avian Diseases 1988, 32, 46.

39. Allgayer, M. C.; Oliveira, S. J.; Mottin, V. D.; Loiko, M.,R.; Abilleira, F.; Guedes, N. M. R.; Passos, D.,T.; Weimer, T. A. Ciência Rural 2009, 39, 2542.

\section{Ronny Morais ${ }^{1}$, Cleber Costa $^{2}$, Eliana Bravo², Antônio Santana', Sebastião Félix², Georgia Sant'Ana ${ }^{2,3}$, Luiz Baptista ${ }^{3}$ \& Carlos Sant'Ana ${ }^{4}{ }^{*}$}

\footnotetext{
${ }^{1}$ Secretaria de Saúde de Anápolis, Vigilância Sanitária, Anápolis-GO. ${ }^{2}$ Faculdade de Tecnologia SENAI Roberto Mange, Anápolis-GO.

3 Jardim Botânico de Goiânia-GO, Agência Municipal do Meio Ambiente (AMMA).

${ }^{4}$ Instituto de Estudos Socioambientais (IESA), Universidade Federal de Goiás, Campus Samambaia, Cx. Postal 131, 74001-970, GoiâniaGO, Brasil.

*e-mail: cersantana@gmail.com
} 